\title{
Study of Energy Conservation and Energy Management Techniques to Be Adopted in YIC Campus
}

\author{
Fahad Albukhari \\ University of Bridgeport, Electrical Engineering Department, Bridgeport, CT USA
}

\begin{abstract}
In this paper, the scarce energy resources, energy conservation has become an important area worldwide. Energy conserved is energy generated. So many companies are putting efforts in this area. Again with the advent of many non-conventional resources, the energy dependence on conventional resources can also be reduced. The project aims at studying one building in YIC campus so that some suggestions can be put forth for conservation. Again energy audit can be carried out to mark the probable areas for energy savings. Energy management techniques can be suggested which may be in the form of installation of wind mills or solar panels to reduce the energy bill.
\end{abstract}

Keywords: Energy audit, Energy Conservation, Techniques, YIC.

\section{INTRODUCTION}

In this era energy conservation has become a priority for each and every organization. Depleting energy resources and pollution has created awareness that steps are to be taken to save energy. Saving energy means generating energy. Energy management is a technique of using energy wisely so that there is no wastage of energy and it is used efficiently and effectively in a justified manner. Energy Audit is a primary step in energy management. In energy audit, the inefficient areas of energy use are spotted and any opportunity of energy saving can be explored. So energy audit and energy management are the two steps in reducing the wastage of energy and using it efficiently. Yanbu Industrial College is an old recognized Institute in Yanbu province of Saudi Arabia. More than 3000 students are studying in this college. It has a area of 25 acres and has 25 buildings in the campus. One of the buildings called OLD ACADEMICS BUILDING is selected for energy audit and energy management. In this era energy conservation has become a priority for each and every organization. Depleting energy resources and pollution has created awareness that steps are to be taken to save energy. Saving energy means generating energy. Energy management is a technique of using energy wisely so that there is no wastage of energy and it is used efficiently and effectively in a justified manner. Energy Audit is a primary step in energy management. In energy audit, the inefficient areas of energy use are spotted and any opportunity of energy saving can be explored [1]. So energy audit and energy management are the two steps in reducing the wastage of energy and using it efficiently. Yanbu Industrial College is an old recognized Institute in Yanbu province of Saudi Arabia. More than 3000 students are studying in this college. It has a area of 25 acres and has 25 buildings in the campus. One of the buildings called OLD ACADEMICS BUILDING is selected for energy audit and energy management. Energy Audit is an effective energy management tool. By identifying and implementing the means to achieve energy efficiency and conservation, not only can energy savings be achieved, but also equipment/system services life can be extended. All these mean savings in money. Based on the principle of "The less energy is consumed, the less fossil fuels will be burnt", the power supply companies will generate relatively less pollutants and by-products. Therefore, all parties concerned contribute to conserve the environment and to enhance sustainable development [2].

In general, it should be assumed that the building manager would have information on general building characteristics and the O\&M personnel would keep the equipment, system technical and operation records. The audit team should determine the appropriate parties to be approached for information collection, the need to discuss with these parties for familiarization of the building, the equipment, systems to be investigated and data verification and the need to discuss with selected end-users. The audit team should consider issuing questionnaires to end-users to collect information on thermal comfort, lighting comfort, operational hours of individual floors/offices, electrical equipment and appliances etc.

After having collected all or the majority of the above information, the audit team will have better understanding of the building context and its energy consuming equipment/systems. With this information, the audit team can better plan subsequent audit activities and detect any missing important datum and arrange to obtain them.

\section{IDENTIFICATION OF EMOS}

To identify the improvement works for the potential EMOs, calculations should be performed to substantiate the improvement works by quantifying energy savings. In evaluating the effectiveness of an EMO, the auditor has to calculate the payback period, net present worth or rate of return. 
Most calculations can be done using simple payback hours are required. Usually, simple instruments such as approach by dividing the EMO's capital cost by the cost of thermometer tube, multi-meters and lux meter will serve anticipated annual energy saving to obtain the payback the purpose.

period in years [3].

However, if there are appreciable deviations between the trends of energy cost and the interest rate or if the capital costs of EMOs are to be injected at different stages with different energy savings achievable at different times, the audit team may have to perform a life cycle cost assessment that can better reflect the cost effectiveness of EMOs. In the energy consumption bills, the measurement dates may not fall on the same day of each month. For more accurate comparison, particularly when different fuel types metered on different dates are involved, these data should be preferably normalized as figures on the common dates. Energy audits aim to improve efficiency but not to save energy by purely sacrificing the standard of service. An EMO should normally not downgrade the quality of service to that below common design standards. Examples of substandard level of comfort include room cooling temperature and air movement rate respectively higher and lower than the recommendations in ASHRAE Standard 55-20044, lighting level below the recommendations in CIBSE Code for Interior Lighting5, excessive noise from equipment/systems causing nuisance, etc. In the past, energy can be saved by limiting the fresh air supply to an $\mathrm{A} / \mathrm{C}$ space. With renewed concerns on good indoor air quality, consideration to provide "adequate fresh air supply" in accordance with the requirements of the Environmental Protection Department (EPD) or ASHRAE Standard 62-20016 should be a foremost thought when degrading to reduce fresh air supply. to which investigations should be conducted and which findings should be analyzed. Based on available resources, the size and type of building, and the energy audit objective, the auditor should adopt the energy audit of different levels of sophistication. Audits may deploy minimum resource to simply check for EMOs that are readily identifiable and to implement them to achieve savings immediately. Under such circumstances, the audit team should carry out a Walk-through Audit. It is the simplest type of energy audit and is the most basic requirement of the energy audit.

The audit should be conducted by walking through the building and concentrating on the major energy consuming equipment/systems such as chillers, large air handling units (AHUs), or common items usually with EMOs easily identifiable such as over-cooled spaces and T8 fluorescent tubes being used. Reference to record of equipment ratings, technical catalogue, O\&M manuals that are readily available will be very helpful to quickly determine where equipment/systems are operating efficiently. Calculations, usually simple in nature, should be done to quantify the saving achievable from implementation of the identified EMOs.

The audit should be carried out in one day by either one auditor or one audit team, depending on the size and the complexity of the building and the scope of the audit. If the audit team wants to check more areas, more auditor-

A Walk-through Audit should, other than fulfilling the original objectives, give an overview of other areas with potential EMOs. Alternatively, if the building management is highly committed to energy conservation and have allowed for adequate staffing and funding, a Detailed Audit should be adopted. The audit team should check practically the majority or all equipment/systems, identify as many EMOs as possible, classify them into different EMO categories, further study if more complex items are involved, formulate a plan for implementation and finally present it to the building management. This audit goes much beyond the Walk-through Audit. The auditor has to exercise more detailed planning. The auditor-hours could be about 5 to 10 times more, depending on the complexity of the equipment/systems involved and size of the building [4].

\section{ENERGY MANAGEMENT TECHNIQUES}

Proposed lighting system - LED Tube sets instead of fluorescent tube sets.LED Tubesets are now becoming popular as energy saving equipments. We have compared wattage of present tube sets with that of diode tube sets to get a replacement of tube light.Detailed savings plan table 1 .

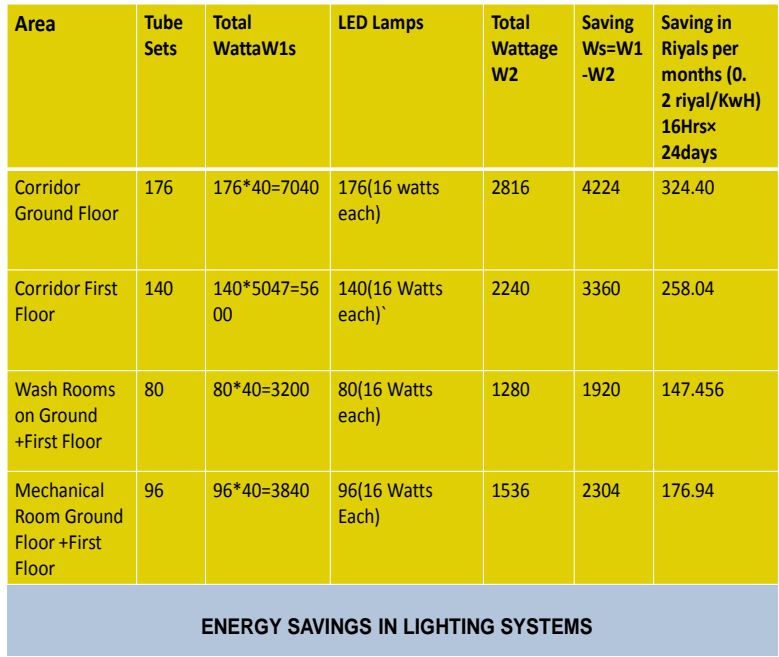

Table 4.1 Energy Savings in Lighting System

Energy Saving by Using Card Switch: Generally, all power is not switched OFF after classroom or Laboratory session.

There are nearly 273 computers in this buildingIn sleep mode each computer will take 10 Watts power, it means total 2730 watts' power is wasted per hour. This power can be saved if card switch is employed in each laboratory, so that, while leaving the laboratory the card is to be removed from the switch and all power is made OFF.Card Switch is an electrical switch which is operated by putting a card inside it, while leaving the room; you have to remove the card figure 1. 


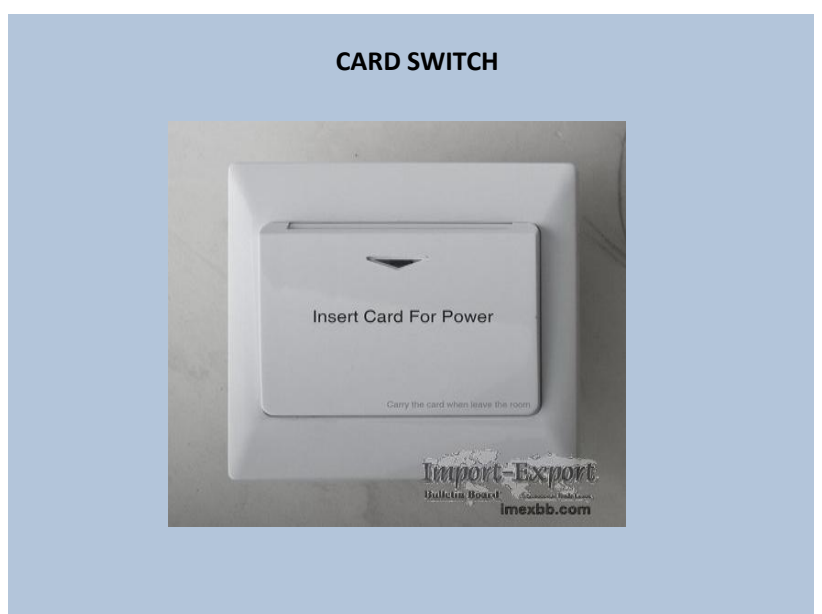

Figure1: Card Switch

Active Filters will remove virtually all distortion. This type of filter is series connected. It measures the waveform distortion continuously and used power electronics to generate a current waveform which is identical but antiphase to that which it is monitoring. When this is injected into the supply it cancels the distortion and the mains input is restored to an almost pure sine wave.

Active Filters are available in a wide range of ratings and can be used on any LV system. When they are correctly rated, active filters will cope with future additions to harmonic generating loads.

Passive Filter - These are designed to remove specific harmonics rather than the full spectrum of distortion. Normally used to eliminate problems and achieve compliance with the distortion limits specified in Engineering Recommendation. Generally more cost effective than Active Filters.Passive filters are one or more circuits comprising capacitor, inductor and sometimes resistor. The values selected are designed to form low impedance paths for specificharmonic frequencies. The harmonic filter, therefore, absorbs a high proportion of the harmonics generated and removes them from the systemThe parameters for design of filter are taken after taking readings by using harmonic analyzer. A filter is designed for one of the feeder where more computer labs are connected.Different Energy Management Techniques to Be Adopted In YIC table 2.

Table 2: Energy Management Techniques to be adopted in YIC

\begin{tabular}{|l|l|l|}
\hline \multicolumn{1}{|c|}{ Without Any Investment } & With Less Investment & $\begin{array}{l}\text { With More } \\
\text { Investment }\end{array}$ \\
\hline $\begin{array}{l}\text { 1. Switching off the electrical loads } \\
\text { when not in use. }\end{array}$ & Use of card switches & $\begin{array}{l}\text { Installation of } \\
\text { Harmonic Filters }\end{array}$ \\
$\begin{array}{l}\text { 2.Educting teachers and students } \\
\text { about energy conservation program }\end{array}$ & & \\
\hline
\end{tabular}

As a result, Lighting and Electronic load form a major part in YIC campus, and Harmonics are found in Old Academics Building [5].

\section{CONCLUSION}

For HVAC Installation, areas of inefficiencies could be identified from data logs of flow rates and corresponding changes in temperatures and pressures. For Electrical Installation, areas of inefficiencies could be identified from data $\operatorname{logs}$ of electrical currents and voltages. If relevant data logs are not available, measurements should be taken to obtain the data of possible inefficient equipment/systems. An opportunity exists to save energy in this campus. LED tube sets looks an attractive opportunity of energy conservation. Harmonic filter is necessary since the electronic load is dominant in YIC

\section{REFERENCES}

[1] Saxena, J. P., \& Vrat, P. (1992). Scenario building: a critical study of energy conservation in the Indian cement industry. Technological Forecasting and Social Change, 41(2), 121-146.

[2] Khudhair, A. M., \& Farid, M. M. (2004). A review on energy conservation in building applications with thermal storage by latent heat using phase change materials. Energy conversion and management, 45(2), 263-275.

[3] Abrahamse, W., Steg, L., Vlek, C., \& Rothengatter, T. (2005). A review of intervention studies aimed at household energy conservation. Journal of environmental psychology, 25(3), 273-291.

[4] Xu, Y., Heidemann, J., \& Estrin, D. (2001, July). Geographyinformed energy conservation for ad hoc routing. In Proceedings of the 7 th annual international conference on Mobile computing and networking (pp. 70-84). ACM.

[5] McCalley, L. T., \& Midden, C. J. (2002). Energy conservation through product-integrated feedback: The roles of goal-setting and social orientation. Journal of economic psychology, 23(5), 589-603. 